\title{
Site-specific gene expression patterns in oral cancer
}

\author{
Gesche Frohwitter $^{1 *}$ (D), Horst Buerger ${ }^{1,2}$, Eberhard Korsching ${ }^{3}$, Paul J. van Diest ${ }^{2}$, Johannes Kleinheinz ${ }^{4}$ \\ and Thomas Fillies ${ }^{5}$
}

\begin{abstract}
Background: Squamous cell carcinomas (SCCS) are the most prevalent malignant tumours within the head and neck. Evidence exists that distinct genes are differentially regulated in SCCs of the oral cavity compared to other head and neck regions. Given this background, the aim of this study was to investigate whether such tumour site-specific gene expression can also be observed in different localizations within the oral cavity.

Methods: Using tissue microarrays (TMAs), we investigated 76 SCCs of the floor of the mouth, 49 SCCs of the tongue and 68 SCCs of other anatomic regions within the oral cavity. The expression of 17 genes involved in cell cycle and growth control (p16, p21, p27, p53, cyclin D1, EGFR, c-kit, bcl-6), cell adhesion (alpha-, beta-, and gamma-catenin), and apoptosis/stress response genes (Hif-1-alpha, Glut 1, CA IX, caspase, hsp70, XIAP) were investigated by means of immunohistochemistry. The data were subjected to $\mathrm{chi}^{2}{ }^{2}$, interdependency and Kaplan-Meier analysis.

Results: Our study suggests a remote difference in the site-specific gene expression patterns of oral cancer. X-linked inhibitor of apoptosis (XIAP) showed a significantly higher expression $(p<0.05)$ in SCCs of the floor of the mouth compared to SCCs of the tongue and other locations within the oral cavity. The increased XIAP expression was further associated with significantly decreased overall survival in all cases of SCCS of the oral cavity ( $p<0.05)$. Expression levels of p53, CA IX, beta-catenin, Hif-1-alpha, and c-kit were also observed to be inversely related between SCCs of the floor of the mouth and those of the tongue respectively, although these differences did not reach statistical significance. Overall and event-free survival did not differ in patients with T1/T2/NO SCCs according to tumour localization.

Conclusion: In summary, the protein expression patterns of SCCS of the oral cavity suggest the existence of a molecular and morphological spectrum of SCCs in the oral cavity. In particular the expression pattern of XIAP indicates distinct gene expression patterns between carcinomas of the floor of the mouth and oral tongue cancer. Further studies are needed to identify possible tumour site-specific factors that influence patient prognosis and management.
\end{abstract}

Keywords: Squamous cell carcinoma, Oral cavity, Location, Tumour biology

\section{Background}

Malignant oral neoplasms are a heterogeneous category of cancer, which are dominated by squamous cell carcinomas (SCCs) [1]. The incidence of oral SCCs has been continuously on the rise, now underlined by representing the tenth most common type of cancer and accounting for 260,000 new cases and 128,000 deaths per year worldwide [2]. To date, surgery has been the benchmark strategy for the primary treatment of oral SCCs, involving

\footnotetext{
* Correspondence: Gesche.Frohwitter@uni-muenster.de

'Institute of Pathology, Husener Str. 46a, 33098 Paderborn, Höxter, Germany Full list of author information is available at the end of the article
}

radical tumour resection, neck dissection, and plastic reconstructive surgery. The extent of surgical therapy required is determined by the spread of the tumour according to TNM-classification after staging as well as for patients with physical and mental strain. Supplemental therapy such as radiation and chemotherapy plays an important role, especially in T3 and T4 tumours as well as in cases with positive lymph nodes, relapses, and palliative situations. Long-term outcome, even in small tumours without histopathologically diagnosed lymph node involvement is highly unpredictable, leading to an overall 5 -year-survival rate of $50 \%$ without any change for the 
last few decades [1,3]. It is therefore important to shed light on the molecular behaviour of cells, proteins, and enzymes involved in oral SCC development and progression to be able to detect patients with highly aggressive cancer and initiate appropriate therapy.

Several studies have reported specific metastatic pathways according to tumour localization and different responses to radiation therapy depending on the anatomical site [4-6]. Belbin et al. showed that specific biological mechanisms underlying tumour aggressiveness are heavily influenced by the site of the primary tumour [7]. Furthermore, it has been reported that oral SCCs of different anatomic locations of the oral cavity express an abnormal amount of cell cycle regulation proteins [8]. We therefore hypothesized that there is a difference in the pattern of molecular tumour development according to the anatomic site. Substantiating this hypothesis was the purpose of our investigation.

\section{Methods}

\section{Patients}

The tested samples were procured by the Institute of Pathology, University of Muenster, Germany. A total of 193 formalin-fixed, paraffin-embedded archival cancer tissue samples of oral SCCs were tested. Details on the clinical procedures and pathological methods of the tumour series are provided in previous publications [9-11]. As shown in Table 1, the series was composed of 193 patients (39 females, 154 males) with a mean age of 59 years (range 31-90 years). The TNM classification of the tumour samples is based on the histopathological tumour evaluation (pTNM). According to the TNM system, the postsurgical classification revealed 96 T1 tumours, 82 T2 tumours, and $15 \mathrm{~T} 3 / 4$ tumours, 136 patients had a negative (N0) locoregional nodal status, whereas 57 patients showed positive $(\mathrm{N}>0)$ locoregional lymph nodes. All patients eligible for the study received continuous follow-up examinations for 4-181 months, the data from patients that failed to regularly attend the follow-up program were not considered after the last regular examination. The time of survival was defined as the period from the surgery day to the date of histologically proven recurrent or metastatic disease, or to the day of death, or to the day of the last follow-up care (60 months post-surgery) [9-11].

\section{Immunohistochemistry}

A total of 193 cancer tissues samples were examined for the expression of p16, p21, p27, p53, cyclin D1, EGFR, ckit, bcl-6, alpha-, beta-, and gamma-catenin, Hif-1-alpha, Glut 1, CA IX, caspase, hsp70, and XIAP.

To ensure identical conditions for the investigation of all tumour specimens, we used tissue microarrays (TMAs) and immunohistochemistry. As described in
Table 1 Tumour patient collective and clinicopathological features of the tumour samples evaluated in the study

\begin{tabular}{ll}
\hline Age at diagnosis (mean) & 59 years (rage 31-90 years) \\
\hline Sex & 39 \\
Female & 154 \\
T stage & \\
T1 & 96 \\
T2 & 82 \\
T3-T4 & 15 \\
N stage & \\
Lymph node negative & 136 \\
Lymph node positive & 57 \\
Grading & \\
G1 & 44 \\
G2 & 126 \\
G3 & 23 \\
Recurrent disease & \\
positive & 68 \\
negative & 127 \\
Localization & \\
Floor of the mouth & \\
Tongue & \\
Other & \\
\hline
\end{tabular}

earlier publications, all TMAs were constructed under a standard protocol [12].

For the preparation of the TMA, each donor block was used to supply the new acceptor block with two punch biopsies measuring $0.6 \mathrm{~mm}$ in diameter. The samples where taken at the tumour margin to ensure consideration of the tumour front in histopathological analysis. Therefore, a special TMA construction tool was used according to the guidelines of Beecher Instruments, New Jersey, USA [12].

The immunohistochemistry was carried out on 4- $\mu \mathrm{m}$ thick sections. The source of the antibodies, clones, dilutions and the antigen retrieval are shown in Table 2. The peroxidase system contained methanol with $0.3 \%$ hydrogen peroxide (Walter-CMP GmbH \& Co. KG) and had an exposure time of $30 \mathrm{~min}$. The expression patterns were evaluated in a semi-quantitative manner.

\section{Scoring}

The thresholds for most markers have been described previously $[9,10,13]$. The expression of cytokeratins was measured by the rate of positively stained cells in each core. CK19 (0\%, no expression; 1-50\%, moderate expression; $>50 \%$, high expression) and in two groups for CK 1, 5/6, 8/18, 10 (0\%, no expression; $\geq 1 \%$, positive 
Table 2 List of antibodies, source, clone, dilution and antigen retrieval applied in the study

\begin{tabular}{|c|c|c|c|c|c|c|c|}
\hline Antibody & Supplier & Catalogue Number & Clone & Mono/Polyclonal & Species & Dilution & Antigen Retrieval \\
\hline p16 & CINTec/Roche & 9517 & $\mathrm{E} 6 \mathrm{H} 4$ & Mono & Mouse & KIT- & Citrate buffer pH6.0 \\
\hline p21 & Merck Millipore & $05-655$ & CP 74 & Mono & Mouse & $1: 500$ & Citrate buffer pH6.0 \\
\hline p27 & $\mathrm{BD} T \mathrm{TL}$ & 610241 & 57/Kip1/p27 & Mono & Mouse & $1: 1000$ & Citrate buffer pH6.0 \\
\hline p53 & Dako & M7001 & DO-7 & Mono & Mouse & $1: 100$ & EDTA pH8.0 \\
\hline Hif-1-alpha & BD TL & 610958 & 54/HIF-1a & Mono & Mouse & $1: 50$ & EDTA pH8.0 \\
\hline Glut 1 & Dako & M 7211 & Clone A 35 & Mono & Mouse & $1: 40$ & EDTA ph8.0 \\
\hline Ca IX & Abcam & ab128883 & - & Poly & Rabbit & $1: 1000$ & Citrate buffer pH6.0 \\
\hline XIAP & BD TL & 610716 & 28/hILP/XIAP & Mono & Mouse & $1: 50$ & Citrate buffer pH6.0 \\
\hline Hsp 70 & Invitrogen & $33-3800$ & $\mathrm{MB}-\mathrm{H} 1$ & Mono & Mouse & $1: 40$ & Citrate buffer pH6.0 \\
\hline a-Catenin & $\mathrm{BD} T \mathrm{TL}$ & 610194 & 5/a-Catenin & Mono & Moue & $1: 250$ & EDTA pH8.0 \\
\hline b-Catenin & $\mathrm{BD} T \mathrm{TL}$ & 610153 & 14/beta-Catenin & Mono & Mouse & $1: 1000$ & EDTA pH8.0 \\
\hline g-Catenin & $\mathrm{BD} T \mathrm{TL}$ & 610253 & 15/g-Catenin & Mono & Mouse & $1: 1500$ & EDTA pH8.0 \\
\hline $\mathrm{BCL}-6$ & Dako & M7211 & PG-B6p & Mono & Mouse & $1: 50$ & Citrate buffer pH6.0 \\
\hline Caspase 3 & Invitrogen & $35-1600 z$ & 43191 & Mono & Mouse & $1: 100$ & Citrate buffer pH6.0 \\
\hline C-kit & Dako & A 4502 & - & Poly & Rabbit & $1: 200$ & Citrate buffer pH6.0 \\
\hline Cyclin D1 & Novocastra & NCL-L-Cyclin D1-GM & P2D11F11 & Mono & Mouse & $1: 20$ & EDTA pH8.0 \\
\hline EGFR & Dako & K 1492 & pharmDX-Kit & Mono & Mouse & $\mathrm{KIT}$ & - \\
\hline
\end{tabular}

expression). The percentage value of two biopsies from one tumour was evaluated. Irrespectively of the number of stained tumour cells cytoplasmatic expression of XIAP, Caspase 3 and Hsp 70 was graded as negative or positive (intermediate to strong expression). CAIX, GLUT 1 and p16/21/27 were rated in two grades (no expression $<1 \%, \geq 1 \%$ positive expression). The following markers were graded in three groups: HIF-1a $(<1 \%$ no expression, low expression $\geq 1 \%-<5 \%$, high expression $\geq$ $5 \%)$, BCL-6, a-Catenin (0-15\% no expression, $16-50 \%$ low expression, $85-100 \%$ positive expression), b-catenin and g-catenin $(0-15 \%$ no expression $16-50 \%$ low expression, 51-100\% high expression). EGFR, Cyclin D1 and C-kit were measured as follows $0-15 \%$ no expression, $16-50 \%$ low expression and $85-100 \%$ positive expression. p53 was rated as no expression $<5 \%$, $\geq 5 \%$ $50 \%$ low expression and $\geq 50 \%$ high positive expression.

\section{Statistical analysis}

Statistical analysis related to clinicopathological factors was performed using $\mathrm{chi}^{2}$ analysis and Kaplan-Meier analysis. A statistical test on differences between the slope of the regression lines was performed (Table 3). The test is based on two linear models: a) y $\sim \mathrm{b} 0+\mathrm{b} 1 \mathrm{x}+$ b2g (null model) and b) y b0 + b1x + b2g + b3xg (alternate model) where $b_{i}$ are the model coefficients, $g$ the grouping factor and $\mathrm{xg}$ the dependency term. Taking the ANOVA/F test on the fit of the two models gives significant differences in our case by assuming alpha values of smaller than 0.05 .
The immunohistochemical data of the TMA tissue was additionally evaluated by an interdependency analysis $[14,15]$. This approach provides the possibility of retrieving the strength of support of a set of molecular markers to a certain anatomic region [16]. Given those differences it can be concluded that the present region owns slightly different molecular regulation schemes. The detailed description of this approach and its application in a clinical setting using TMA data has been provided previously [17-19].

\section{Results}

The results of the immunohistochemical expression patterns according to different tumour locations are summarized in Table 4. Examples of positive immunohistochemical stainings of oral SSC with XIAP, p53 and CAIX antibodies are given in Fig. 1.

The results of the interdependency analysis for the different expression patterns of SCCs in various locations of the oral cavity are shown in Fig. 2. Two different test sets have been generated, containing 9 and 8 test markers, respectively. The correlation between the

Table $\mathbf{3}$ Test on significant different slope

\begin{tabular}{llll}
\hline & Floor of the mouth & Tongue & Other \\
\hline Floor of the mouth & 0 & 0 & 0 \\
Tongue & $6.9 \mathrm{e}-07$ & 0 & 0 \\
Other & $3.1 \mathrm{e}-02$ & 0.11 & 0 \\
Tongue & $1.2 \mathrm{e}-07$ & 0 & 0 \\
Other & $5.8 \mathrm{e}-03$ & 0.025 & 0 \\
\hline
\end{tabular}


Table 4 Expression profile of antibodies at different tumour localizations used in the study and measured in per cent/p value/r value

\begin{tabular}{llll}
\hline Antibody & $\begin{array}{l}\text { Floor of the mouth } \\
\text { positive expression }\end{array}$ & $\begin{array}{l}\text { Tongue positive } \\
\text { expression }\end{array}$ & $\begin{array}{l}\text { Other positive } \\
\text { expression }\end{array}$ \\
\hline p16 & $22.4 / 0.67 / 0.03$ & $18.6 / 0.64 /-0.03$ & $22.9 / 0.72 / 0.03$ \\
p21 & $70.6 / 0.82 /-0.02$ & $73.8 / 0.76 / 0.02$ & $75.5 / 0.61 / 0.04$ \\
p27 & $19.7 / 0.59 / 0.04$ & $20 / 0.95 / 0$ & $18.4 / 0.93 / 0.01$ \\
p53 & $52,9 / 0.21 / 0.09$ & $85.7 / 0.46 /-0.05$ & $55 / 0.32 /-0.07$ \\
Hif-1-alpha & $63.2 / 0.27 / 0.08$ & $44.9 / 0.11 /-0.12$ & $59.1 / 0.7 / 0.03$ \\
Glut 1 & $90.0 / 0.28 / 0.08$ & $85.7 / 0.3 /-0.07$ & $96,9 / 0.84 /-0.01$ \\
Ca IX & $22.1 / 0.2 /-0.09$ & $33.3 / 0.17 / 0.1$ & $27 / 1 / 0$ \\
XIAP & $30.0 / 0.01 / 0.18$ & $13.2 / 0.31 /-0.07$ & $12.5 / 0.04 / 0.15$ \\
Hsp 70 & $10.8 / 0.89 /-0.01$ & $10.3 / 0.61 /-0.04$ & $10.9 / 0.34 /-0.07$ \\
a-Catenin & $64.8 / 0.71 /-0.03$ & $65.9 / 0.91 / 0.01$ & $65.7 / 0.91 /-0.01$ \\
b-Catenin & $84.5 / 0.78 /-0.02$ & $86.7 / 0.09 / 0.12$ & $82.1 / 0.08 /-0.13$ \\
g-Catenin & $66.7 / 0.98 / 0$ & $64.3 / 0.84 / 0.02$ & $63.6 / 0.89 / 0.01$ \\
BCL-6 & $25.8 / 0.63 / 0.03$ & $18.2 / 0.58 /-0.04$ & $19.1 / 0.84 /-0.01$ \\
Caspase 3 & $32.8 / 0.07 / 0.07$ & $21.1 / 0.3 /-0.03$ & $22 / 0.3 /-0.01$ \\
C-kit & $16.2 / 0.49 / 0.05$ & $6.8 / 0.36 /-0.07$ & $15.4 / 0.26 / 0.08$ \\
Cyclin D1 & $51,5 / 0.63 /-0.03$ & $45.5 / 0.44 / 0.06$ & $50 / 0.72 /-0.03$ \\
EGFR & $81.2 / 0.91 / 0.01$ & $68.2 / 0.56 /-0.04$ & $73.5 / 0.85 / 0.01$ \\
\hline
\end{tabular}

test marker ( $\mathrm{x}$-axis) and the location surrogate marker is shown on the $y$-axis. The first test set included cell cycle control proteins and two growth factor receptors. In the second set genes involved in cellular stress responses, apoptosis, and cell adhesion were investigated.

In the first marker set only minor differences between the different tumour localizations could be observed (Fig. 2a). SCCs of the floor of the mouth and of the tongue showed opposing regression curves. In SCCs of the floor of the mouth positive correlation coefficients were observed for $\mathrm{p} 53$ and c-kit, whereas the expression of these protein showed a negative correlation in SCCs of the tongue. A similar but inverse pattern was revealed for cyclin D1 expression. The regression curve for SCCs of various other localizations within the oral cavity did not reveal any significant regression trends.

The second test set (Fig. 2b) showed more prominent differences in the behaviour of the test markers. HIF-1alpha and XIAP had a remarkable and different regulatory role in SCCs of the floor of the mouth and tongue, whereas the appearance of XIAP in other tumour localizations had no impact $(p<0.05)$, Fig. $2 \mathrm{~b}$. Furthermore, the expression of XIAP was associated with a poor prognosis in all SCCs of the oral cavity $(p<0.05)$, as shown in Fig. 3.
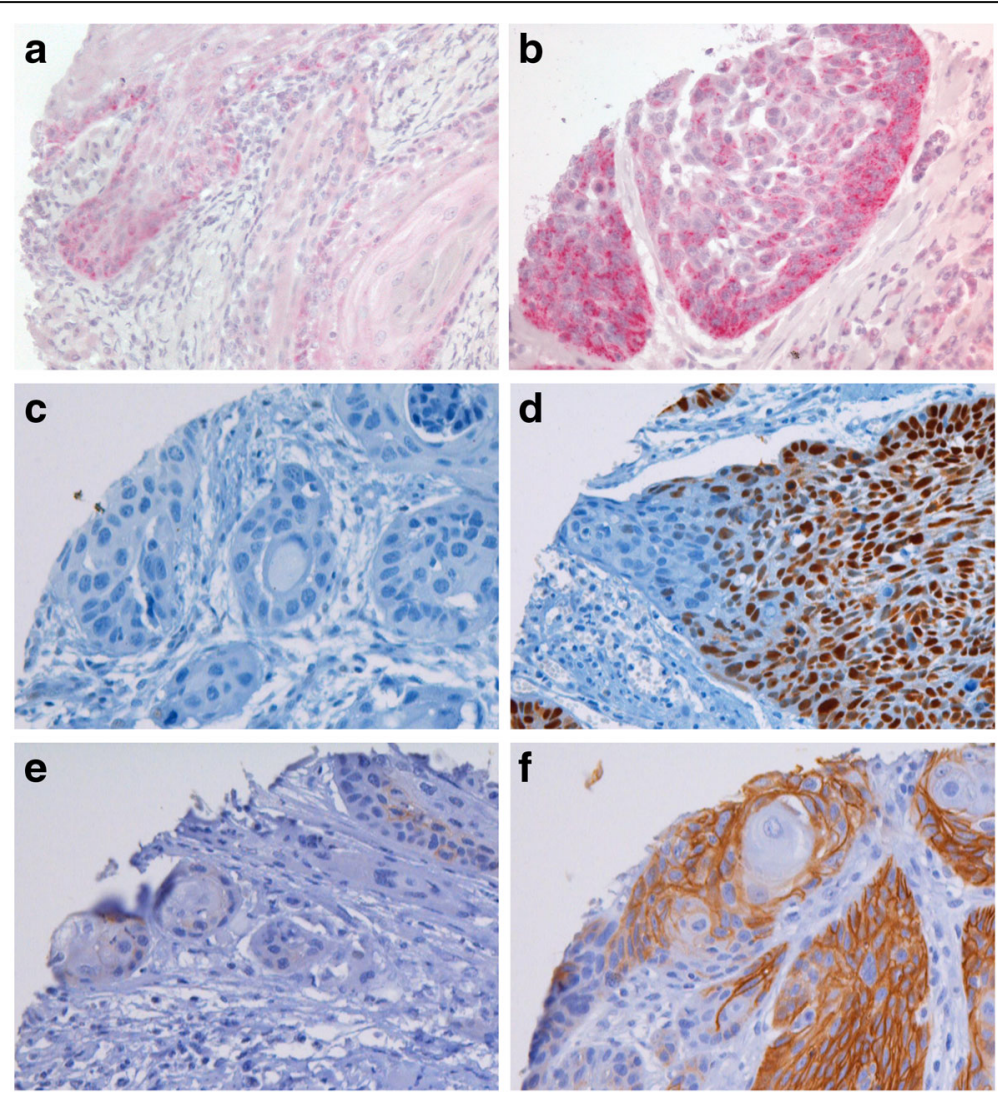

Fig. 1 Examples of positive immunohistochemical staining of oral squamous cell carcinomas with XIAP, p53 and CAIX antibodies. a weak XIAP expression, b strong XIAP expression, c weak p53 expression. $\mathbf{d}$ strong p53 expression, e weak CAIX expression, $\mathbf{f}$ strong CAIX expression 

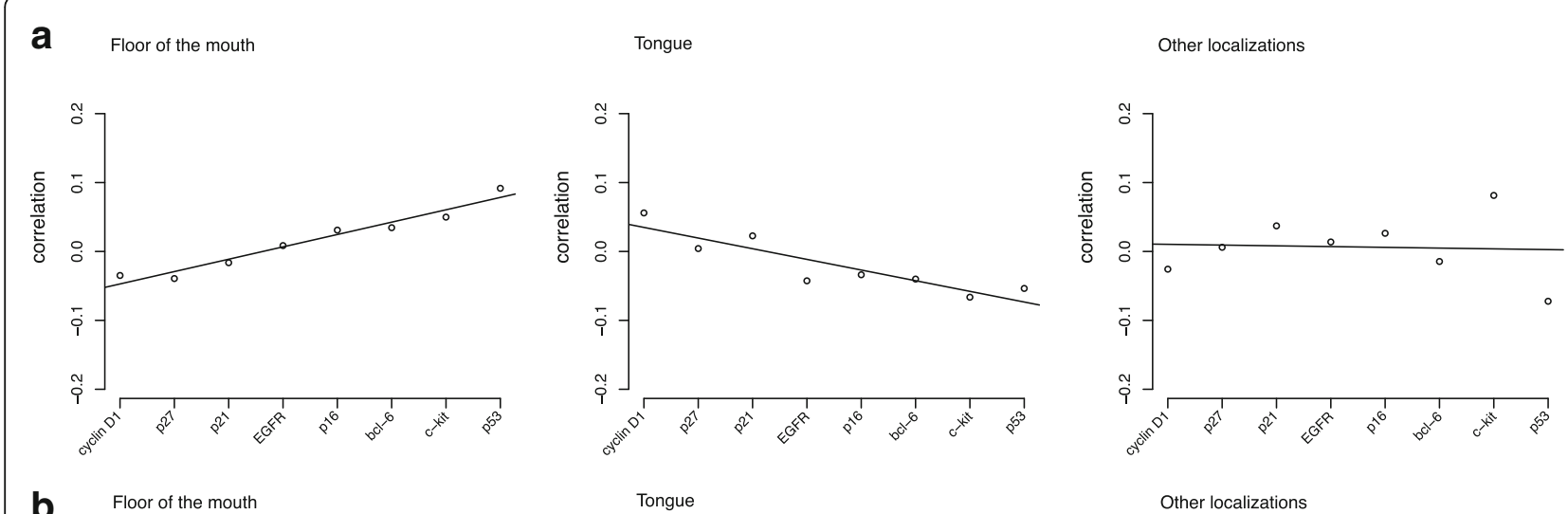

b Floor of the mouth

Tongue
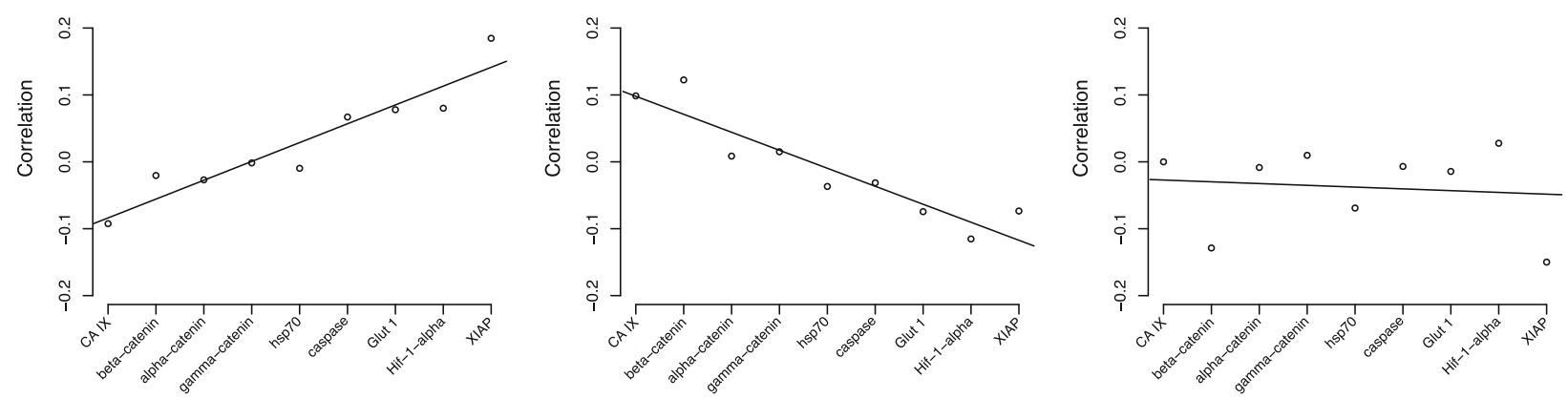

Fig. 2 Regression curves of the evaluated tumour samples examined by permutation analysis. a Protein expression of different anatomical subsites analysed according to cell cycle and growth control regulation proteins. b Protein expression of different anatomical subsites analysed according to genes involved in cellular stress responses, apoptosis and cell adhesion

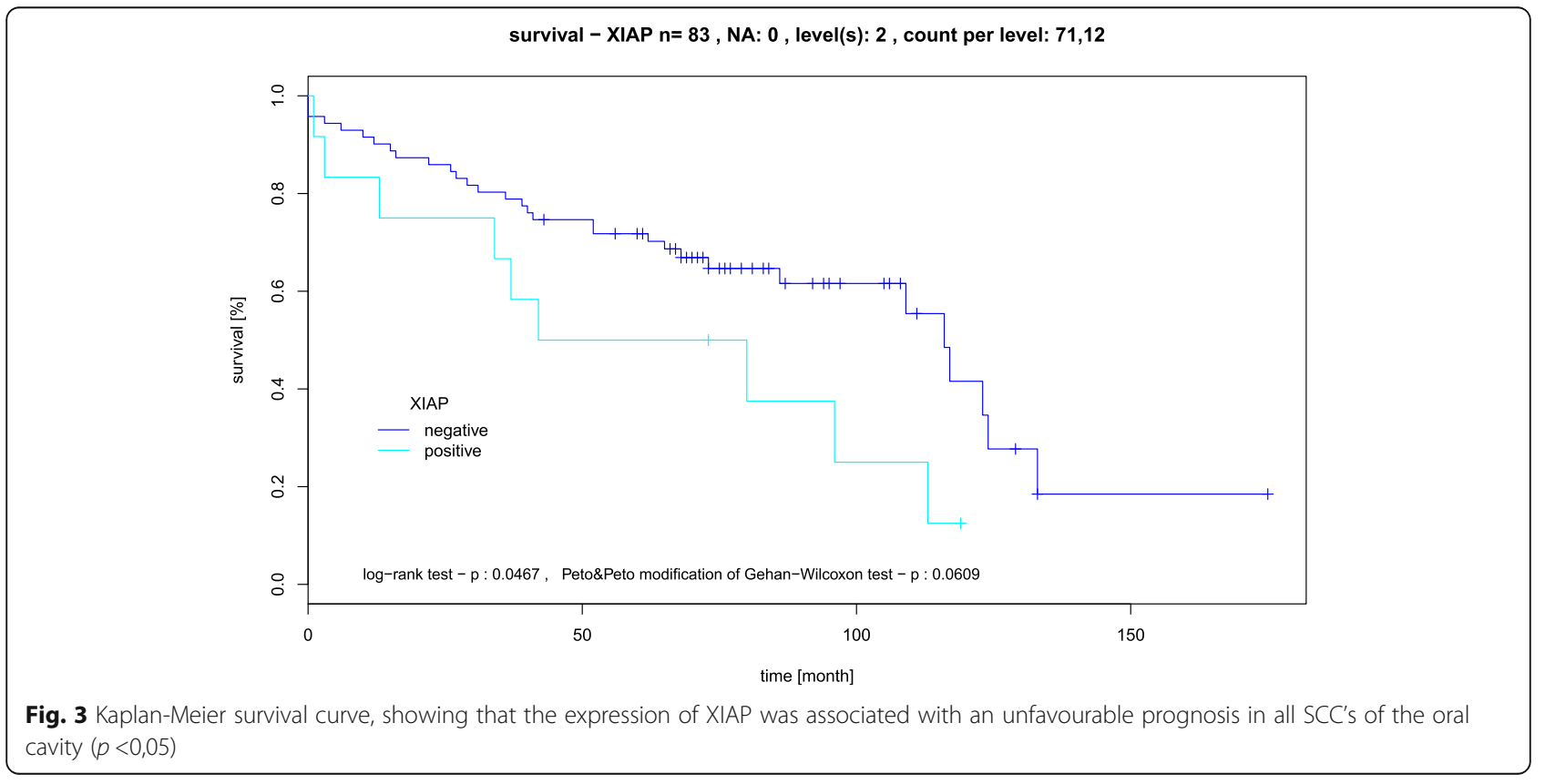


As demonstrated in Fig. 2b, SCCs of the tongue showed positive expression of CA IX and beta-catenin. The regression curve for the SCCs of other localizations within the oral cavity did not reveal to differentiate gene expression patterns in relation to tumour localization.

Table 3 shows the test on significant different slope.

Table 4 shows the expression profile of antibodies at different tumour localizations measured in per cent. Taking $\mathrm{XIAP}$ as an example, the positive staining results for the floor of the mouth (30\%) in comparison those for the oral tongue $(13.2 \%)$ and other tumour localizations $(12.5 \%)$ were consistent with the regression curves shown in Fig. $2 \mathrm{~b}$.

In summary, the opposing trends of the regression curves for SCCs of the floor of the mouth and of the tongue indicate a slightly different regulatory role of XIAP as a tumour marker.

However, overall and event-free survival did not differ in patients with T1/T2/N0 SCCs according to tumour localization (Fig. 4).

\section{Discussion}

SCCs of the oral cavity account for more than $90 \%$ of all malignant neoplasms in this anatomic region. Apart from Asian, countries where buccal oral SCCs rank first on the list of anatomical sites, in Western countries, the oral tongue is most frequently affected $(40-50 \%)$ followed by the floor of the mouth $[3,20]$. These differences appear to be mainly due to various exogenous risk factors rather than an intrinsic molecular ethnic background [3, 21]. Hence, the data suggest the possibility of the existence of multiple lines of evolution of oral SCCs according to their anatomic localization and the presence of respective risk factors. From a histomorphological point of view, SCCs of the head and neck region, including the oral cavity, are typed and graded similarly suggesting related underlying tumour biology. However, recent evidence has demonstrated SCCs of the oral cavity and the head and neck region might actually be different tumour entities at the molecular level [22, 23].

Belbin at al. detected altered gene expression levels at different anatomic sites in the head and neck by examining the whole RNA sequence of 45 head and neck SCCs compared to samples of a healthy control group. Out of the wide range of genes identified, Belbin et al. extracted TGF $\beta$, IL 1, and matrix metalloproteinases as typical of oral SCCs, PCK, IL 8, and FGFR 1 as characteristic genes of oropharyngeal SCCs, and IL 6, p53, and PRLR as representative of hypopharyngeal and laryngeal SCCs, suggesting distinctive hallmarks for each anatomical subsite in head and neck SCCs [7]. In 2011, Boldrup et al. emphasized the importance of differentiating the anatomical subsites as well as the histological mucosa conditions to sufficiently evaluate the histomorphological patterns of head and neck cancer [8]. Furthermore, the outcome of radiation therapy in advanced disease has been suggested to be associated with the anatomic location of the tumour [6].

Our own results as well as those described above support our theory that tumour development in the head and neck area can be evaluated as a single interlocked path affected by exposure to carcinogenic substances. However, the individual tumour growth patterns and hence the highly variable therapy responses observed may be influenced by other factors.

Based on these observations, we evaluated whether SCCs of different anatomic localizations within the oral cavity might also differ with respect to their molecular background. The molecular biology of malignant tumours often determines the clinical behaviour and long-term

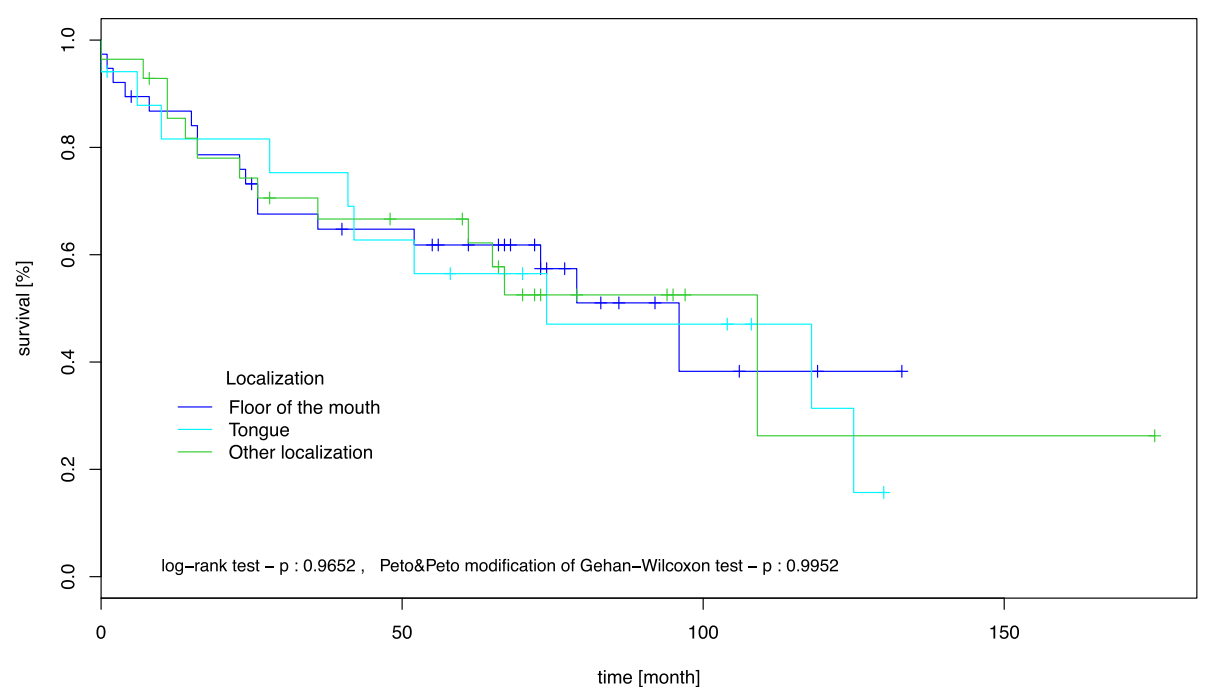

Fig. 4 Kaplan-Meier survival curve, showing that overall and event-free survival did not differ in patients with T1/T2/NO SCCS according to tumour localization 
outcome. With our first approach, we were able to show that the overall and event-free survival did not differ in patients with T1/T2/N0 SCCs according to tumour localization (Fig. 4).

Using the TMA technique and a set of 17 different antibodies, we were able to show that different anatomic localizations within the oral cavity seem to be associated with slightly different molecular expression patterns. TMA is a profound method to evaluate immunohistochemical patterns in large numbers of tumour samples $[12,16]$. Even though the method might be questionable when evaluating heterogeneous tissue or a single histopathological sample, the size of our patient collective $(n=$ 193) as well as the statistical methods applied spares the idea of non-significant punch biopsies [15]. In particular SCCs of the floor of the mouth and the tongue showed different protein regulation patterns. For example, XIAP was strongly expressed in carcinomas of the floor of the mouth, an inverse result could be observed in SCCs of the tongue (Fig. 2b). XIAP is known as a member of the inhibitors of apoptosis family that compromises eight proteins preventing caspase activation. Furthermore, XIAP can affect initiator and effector caspases, and is capable of inhibiting the intra- and extramitochodrial apoptotic pathway [24]. The suppression of caspase 3, 7, and 9 activation favours tumour growth and also strengthens the resistance of tumour cells against the effects of cisplatin-based chemotherapy in advanced oral SCCs and oesophageal SCCs $[25,26]$. Hence, XIAP expression contributes to a more resistant tumour with a lower response to adjuvant radiation therapy. However, due to the diversity of genes involved in tumour development and progression, it cannot be conclusively stated, that carcinomas of the floor of the mouth behave more aggressively than tongue carcinomas (Fig. 4). Nevertheless, one has to keep in mind, that the expression of XIAP without any relation to the tumour site did result in a decreased overall survival (Fig. 3).

Similar findings and tendencies could be observed for the expression levels of p53, CA IX, beta-catenin, Hif-1alpha, and c-kit in both localizations.

Hypoxia inducible factor (HIF) is a heterodimer protein consisting of a three-part alpha subunit and a single beta subunit. In hypoxemia, induced cell stress, Hif-1-alpha functions as a transcription factor. As oxygen levels decrease, the alpha subunit accumulates with the beta subunit, transfers to the nucleus, and activates the hypoxiaresponsive element that operates as a transcription factor. The upregulation of Glut 1, VEGFR, CA IX, erythropoietin, heat shock proteins, and other cell growth factors affect protein expression and activation. This cascade is involved in the differentiation of embryonic stem cells, bones, blood vessels, and organs as well as in tumour cells with underlining similarities in growth habits, leading to fast tumour progression [27-33]. Again, these findings are not able to confirm the extent of tumour aggressiveness in relation to its localization, but nevertheless point towards a complex pattern of gene interaction that varies even with respect to the anatomical subsite.

The other markers also showed globally differing regulation patterns but with lower impact. The interdependency analysis, which is a statistical tool used to reveal small differences in regulatory pathways, indicated that there are different underlying molecular mechanisms in SCCs of the floor of the mouth and the tongue. The regression curves showed an almost antagonistic protein expression profile between floor of the mouth cancer and oral tongue cancer. However, it has to be stated that the chi ${ }^{2}$ analysis only showed statistical significance for the differential expression of XIAP.

Using interdependency analysis in invasive breast cancer the existence of a number of independent, parallel progression pathways was identified [34]. Therefore, we cannot conclusively interpret the slightly opposing regression curves in SCCs of the floor of the mouth and the tongue, as well as the other anatomic sites, as clear evidence for multiple, independent progression pathways in SCCs of the oral cavity. Instead, we consider that our results point to a molecular and morphological spectrum of SCCs, with a possible influence of so far unknown site-specific factors on commonly shared tumour biological mechanisms. Further research is required to assess the importance of molecular site-specific tumour patterns in practice.

\section{Conclusion}

In summary, we analysed 193 SCCs with a focus on 17 different protein expression patterns in relation to the anatomical location within the oral cavity using a sophisticated biomathematical algorithm. Our results point towards a wide molecular spectrum of SCCs in the oral cavity. Even though the carcinomas showed a large range of protein expression, only minimal sitespecific protein mechanisms could be detected that could potentially reflect the different clinical behaviours of SSCs within the oral cavity. For T1/T2/N0 tumours no significant difference in tumour site-specific survival could be seen. Further studies are needed to define possible tumour site-specific factors with relevance for patient prognosis and management.

\footnotetext{
Abbreviations

Bcl-6: B-cell lymphoma-6 cell adhesion; CA IX: Carbonic anhydrase 9; Ckit: Mast/stem cell growth factor receptor; EGFR: Epithelial growth factor receptor; Glut 1: Glucose transporter 1; Hif-1-alpha: Hypoxia inducible factor 1-alpha; Hsp70: Heat shock protein 70; SCCs: Squamous cell carcinomas; TMAs: Tissue mircoarrays; XIAP: X-linked inhibitor of apoptosis protein
}

Acknowledgements

No acknowledgements. 


\section{Funding}

No funding.

\section{Availability of data and materials}

Available upon request. For further information please contact the corresponding author.

\section{Authors' contribution}

GF Project planning, data analysis and interpretation, writing of the main part of the manuscript. HB Project planning, data collection, data analysis and interpretation, writing of the manuscript. EK Data analysis and interpretation, critical appraisal of the manuscript. PVD Critical appraisal of the manuscript. JK Critical appraisal of the manuscript. TF Project planning, data collection, writing of the manuscript. All authors read and approved the final manuscript.

\section{Competing interests}

The authors declare that they have no competing interests.

\section{Consent for publication}

Not applicable.

\section{Ethics approval and consent to participate}

The data collection and evaluation was conducted in compliance with the current revision of the Declaration of Helsinki and with the International Conference for Harmonisation Good Clinical Practice (ICH-GCP). Ethical approval was given by the ethical commission of the medical association Westfalen-Lippe and the Faculty of Medicine of the Westphalian WilhelmsUniversity Muenster, Germany. Written informed consent was obtained from the participants.

\section{Publisher's Note}

Springer Nature remains neutral with regard to jurisdictional claims in published maps and institutional affiliations.

\section{Author details}

'Institute of Pathology, Husener Str. 46a, 33098 Paderborn, Höxter, Germany. ${ }^{2}$ Institute of Pathology, University of Utrecht, Utrecht, The Netherlands. ${ }^{3}$ Institute of Bioinformatics, University of Muenster, Muenster, Germany. ${ }^{4}$ Department of Cranio- and Maxillofacial Surgery, University Hospital Muenster, Muenster, Germany. ${ }^{5}$ Department of Cranio- and Maxillofacial Surgery, Marienhospital Stuttgart, Stuttgart, Germany.

\section{Received: 12 May 2016 Accepted: 19 April 2017}

Published online: 10 May 2017

\section{References}

1. Scully C, Bagan J. Oral squamous cell carcinoma overview. Oral Oncol. 2009; 45:301-8.

2. Jemal A, Bray F, Center MM, Ferlay J, Ward E, Forman D. Global cancer statistics. CA Cancer J Clin. 2011;61:69-90.

3. Warnakulasuriya S. Global epidemiology of oral and oropharyngeal cancer. Oral Oncol. 2009:45:309-16.

4. Lindberg R. Distribution of cervical lymph node metastases from squamous cell carcinoma of the upper respiratory and digestive tracts. Cancer. 1972;29: $1446-9$.

5. Woolgar JA. Histological distribution of cervical lymph node metastases from intraoral/oropharyngeal squamous cell carcinomas. Br J Oral Maxillofac Surg. 1999;37:175-80.

6. Lin CY, Wang HM, Kang CJ, Lee LY, Huang SF, Fan KH, Chen EY, Chen $\mathbb{H}_{\text {, }}$ Liao CT, Chang JT. Primary tumor site as a predictor of treatment outcome for definitive radiotherapy of advanced-stage oral cavity cancers. Int J Radiat Oncol Biol Phys. 2010;78:1011-9.

7. Belbin TJ, Schlecht NF, Smith RV, Adrien LR, Kawachi N, Brandwein-Gensler M, Bergman A, Chen Q, Childs G, Prystowsky MB. Site-specific molecular signatures predict aggressive disease in HNSCC. Head Neck Pathol. 2008;2: 243-56

8. Boldrup L, Coates PJ, Laurell G, Nylander K. Differences in p63 expression in SCCHN tumours of different sub-sites within the oral cavity. Oral Oncol. 2011;:47:861-5.
9. Fillies T, Woltering M, Brandt B, Van Diest JP, Werkmeister R, Joos U, Buerger H. Cell cycle regulating proteins p21 and p27 in prognosis of oral squamous cell carcinomas. Oncol Rep. 2007;17:355-9.

10. Fillies T, Werkmeister R, van Diest PJ, Brandt B, Joos U, Buerger H. HIF1-alpha overexpression indicates a good prognosis in early stage squamous cell carcinomas of the oral floor. BMC Cancer. 2005;5:84.

11. Fillies $T$, Werkmeister $R$, Packeisen J, Brandt B, Morin P, Weingart D, Joos U, Buerger $\mathrm{H}$. Cytokeratin 8/18 expression indicates a poor prognosis in squamous cell carcinomas of the oral cavity. BMC Cancer. 2006;6:10.

12. Packeisen J, Buerger $\mathrm{H}$, Krech $\mathrm{R}$, Boecker $\mathrm{W}$. Tissue microarrays: a new approach for quality control in immunohistochemistry. J Clin Pathol. 2002;55:613-5.

13. Fillies T, Buerger H, Gaertner C, August C, Brandt B, Joos U, Werkmeister R. Catenin expression in T1/2 carcinomas of the floor of the mouth. Int J Oral Maxillofac Surg. 2005;34:907-11.

14. Team RC. A language and environment for statistical computing. In Book A language and environment for statistical computing (Editor ed.^eds.), 3.1.3 edition. City: R Foundation for Statistical Computing; 2015.

15. Boecker $F$, Buerger $H$, Mallela NV, Korsching E. TMAinspiration: decode interdependencies in multifactorial tissue microarray data. Cancer Informat. 2016;29(15):143-9.

16. Packeisen J, Korsching E, Herbst H, Boecker W, Buerger H. Demystified. . tissue microarray technology. Mole Pathol. 2003;56:198-204.

17. Schymik B, Buerger H, Kramer A, Voss U, van der Groep P, Meinerz W, van Diest PJ, Korsching E. Is there 'progression through grade' in ductal invasive breast cancer? Breast Cancer Res Treat. 2012;135:693-703.

18. Buerger H, Boecker F, Packeisen J, Agelopoulos K, Poos K, Nadler W, Korsching E. Analyzing the basic principles of tissue microarray data measuring the cooperative phenomena of marker proteins in invasive breast cancer. Open Access Bioinformatics 5.1 (2013):1-21.

19. Boecker F, Buerger H, Mallela NV, Korsching E. TMA inspiration: Decode interdependencies in multi-factorial tissue microarray data. Cancer Inform. 2016;15:143-9. doi:10.4137/CIN.S39112.

20. Li R, Koch WM, Fakhry C, Gourin CG. Distinct Epidemiologic Characteristics of Oral Tongue Cancer Patients. Otolaryngol Head Neck Surg. 2013;148(5): 792-6. doi:10.1177/0194599813477992.

21. Su CC, Yang HF, Huang SJ, Lian le B. Distinctive features of oral cancer in changhua county: high incidence, buccal mucosa preponderance, and a close relation to betel quid chewing habit. J Formos Med Assoc = Taiwan yi zhi. 2007;106:225-33.

22. Habbous S, Harland LT, La Delfa A, Fadhel E, Xu W, Liu FF, Goldstein D, Waldron J, Huang SH, B OS, Liu G. Comorbidity and prognosis in head and neck cancers: Differences by subsite, stage, and human papillomavirus status. Head Neck. 2014;36(6):802-10. doi:10.1002/hed.23360.

23. Rampias T, Pectasides E, Prasad M, Sasaki C, Gouveris P, Dimou A, Kountourakis P, Perisanidis C, Burtness B, Zaramboukas T, et al. Molecular profile of head and neck squamous cell carcinomas bearing p16 high phenotype. Ann Oncol. 2013;24(8):2124-31. doi:10.1093/annonc/mdt013.

24. Liston P, Fong WG, Kelly NL, Toji S, Miyazaki T, Conte D, Tamai K, Craig CG, McBurney MW, Korneluk RG. Identification of XAF1 as an antagonist of XIAP anti-caspase activity. Nat Cell Biol. 2001;3:128-33.

25. Yang XH, Feng ZE, Yan M, Hanada S, Zuo H, Yang CZ, Han ZG, Guo W, Chen WT, Zhang P. XIAP is a predictor of cisplatin-based chemotherapy response and prognosis for patients with advanced head and neck cancer. PLoS One. 2012;7:e31601.

26. Zhang S, Ding F, Luo A, Chen A, Yu Z, Ren S, Liu Z, Zhang L. XIAP is highly expressed in esophageal cancer and its downregulation by RNAi sensitizes esophageal carcinoma cell lines to chemotherapeutics. Cancer Biol Ther. 2007;6:973-80.

27. lyer NV, Leung SW, Semenza GL. The human hypoxia-inducible factor 1alpha gene: HIF1A structure and evolutionary conservation. Genomics. 1998;52:159-65.

28. Wang GL, Semenza GL. Characterization of hypoxia-inducible factor 1 and regulation of DNA binding activity by hypoxia. J Biol Chem. 1993;268:21513-8.

29. Semenza GL. Regulation of mammalian $\mathrm{O} 2$ homeostasis by hypoxia-inducible factor 1. Annu Rev Cell Dev Biol. 1999;15:551-78.

30. Bentovim L, Amarilio R, Zelzer E. HIF1alpha is a central regulator of collagen hydroxylation and secretion under hypoxia during bone development. Development. 2012;139:4473-83.

31. Flamme I, Frohlich T, von Reutern M, Kappel A, Damert A, Risau W. HRF, a putative basic helix-loop-helix-PAS-domain transcription factor is closely related to hypoxia-inducible factor-1 alpha and developmentally expressed in blood vessels. Mech Dev. 1997;63:51-60. 
32. Gassmann M, Fandrey J, Bichet S, Wartenberg M, Marti HH, Bauer C, Wenger $\mathrm{RH}$, Acker $\mathrm{H}$. Oxygen supply and oxygen-dependent gene expression in differentiating embryonic stem cells. Proc Natl Acad Sci U S A. 1996;93: 2867-72.

33. Haase VH. Hypoxia-inducible factors in the kidney. Am J Physiol Renal Physiol. 2006;291:F271-81.

34. Korsching E, Packeisen J, Agelopoulos K, Eisenacher M, Voss R, Isola J, van Diest PJ, Brandt B, Boecker W, Buerger H. Cytogenetic alterations and cytokeratin expression patterns in breast cancer: integrating a new model of breast differentiation into cytogenetic pathways of breast carcinogenesis. Lab Invest. 2002;82:1525-33.

Submit your next manuscript to BioMed Central and we will help you at every step:

- We accept pre-submission inquiries

- Our selector tool helps you to find the most relevant journal

- We provide round the clock customer support

- Convenient online submission

- Thorough peer review

- Inclusion in PubMed and all major indexing services

- Maximum visibility for your research

Submit your manuscript at www.biomedcentral.com/submit 